\title{
Towards a (De)centralisation-Based Typology of Peer Production
}

\author{
Mélanie Dulong de Rosnay ${ }^{*}$ and Francesca Musiani ${ }^{* *}$ \\ "ISCC, CNRS/Paris-Sorbonne/UPMC, Paris, France, melanie.dulong@cnrs.fr, \\ http://www.iscc.cnrs.fr/spip.php?article1558 \\ "ISCC, CNRS/Paris-Sorbonne/UPMC, Paris, France, francesca.musiani@cnrs.fr, \\ http://www.csi.mines-paristech.fr/People/musiani
}

\begin{abstract}
Online peer-production platforms facilitate the coordination of creative work and services. Generally considered as empowering participatory tools and a source of common good, they can also be, however, alienating instruments of digital labour. This paper proposes a typology of peerproduction platforms, based on the centralisation/decentralisation levels of several of their design features. Between commons-based peer-production and crowdsourced, user-generated content "enclosed" by corporations, a wide range of models combine different social, political, technical and economic arrangements. This combined analysis of the level of (de)centralisation of platform features provides information on emancipation capabilities in a more granular way than a market-based qualification of platforms, based on the nature of ownership or business models only. The five selected features of the proposed typology are: ownership of means of production, technical architecture/design, social organization/governance of work patterns, ownership of the peer-produced resource, and value of the output.
\end{abstract}

Keywords Peer production, P2P, Platforms, Distributed Architectures, Ownership, Governance, Design, Copyright, Commons

Acknowledgments This research was initiated as part of the ADAM interdisciplinary project on Distributed Architectures and Multiple Multimedia Applications supported by a grant from the French ANR (Agency for National Research). It has been further supported by the Framework Programme FP7-ICT-2013-10 of the European Commission through the project P2Pvalue (grant no.: 610961) and the EINS network of the European Commission on Internet Science. Earlier versions of the typology were presented at the following conferences: the 2012 SCRIPT Conference, Law and Transformation, Arts and Humanities Research Council Centre for Studies in Intellectual Property and Technology Law at the University of Edinburgh; the 2013 EINS First Conference on Internet Science in Brussels; the 2013 Fourth Annual Transforming Audiences Conference, University of Westminster, London; and the Cost Action 2015 workshop on Digital Labour in Brussels. Authors are grateful for comments received during these events and provided by Bingchun Meng, the reviewers and editor.

\section{Introduction}

The increasing importance of peer production in contemporary societies is leading to the rise of an emerging field of peer production studies, with its conferences, ${ }^{1}$ journals ${ }^{2}$ and dedicated research projects, ${ }^{3}$ aimed at analyzing "the forms, operations, and contradictions of peer producing communities in contemporary capitalist society". ${ }^{4}$ This complexification entails both an opportunity and a challenge for peer-to-peer researchers and practitioners faced with the need to clarify their research objects, their research questions, and the methodological tools that are best suited to addressing these.

This article proposes to embrace this variety, as reflected in the recent proliferation of peer-production arrangements (Botsman 2013), and intends to contribute to its systematiza-

\footnotetext{
${ }^{1}$ E.g. the Oekonux Conference, http://www.oekonux-conference.org/

2 E.g. Journal of Peer Production, http://www.peerproduction.net

${ }^{3}$ E.g. P2Pvalue, http://www.p2pvalue.eu/

${ }^{4}$ Mission Statement, Journal of Peer Production: http://peerproduction.net/about/mission-statement/
} 
tion. To this end, we propose a typology of peer-production platforms that untangles various features and components of this mode of production, choosing to analyse these in terms of architecture, ownership, governance and value-creation also outside of capitalism, and according to their degree of (de)centralisation.

As most peer-production platforms share the objective of encouraging participation and facilitating collaboration, we consider it more suitable, for the purpose of a first classification or systematization, to concentrate at this stage on the different organizational and procedural forms that take shape within the realm of peer production. Indeed, the same objectives of participation and collaboration may be achieved through different combinations of rules, governance, ownership and architectural design, in continuums ranging from completely centralised to completely decentralised. The extremes of each continuum, merging to form ideal types of peer production organization, form the core of the typology and will be described in detail later; to provide an example, technical architecture will range from centralised arrangements, controlled by a single entity (usually a server or group of servers), to decentralised arrangements that will distribute the resources at the periphery or "edge" of the network.

Illustrating our typology by means of several examples, we establish a classification of peer-production platforms. This typology is expected to provide a critical perspective on peerproduction design in order for platforms developers, users and regulators to better understand which parameters may facilitate for-profit crowdsourcing, exclusion and exploitation, or, on the contrary, support collective governance of commons-based peer production and value-generation. More broadly, our aim is to contribute to the untangling of concepts such as the sharing economy, participation, collaboration and the commons, through the analysis and systematization of several factors underlying the platforms where such processes take place and appreciate value outside of individual gain.

This typology is proposed as an explanatory methodological tool for future research in peer production, and may ultimately be useful in order to better understand, if not fully explain, and assess the impact of underlying organizational forms and design on peer production.

\section{Theoretical Foundations}

Our work builds upon several different strands of literature. Previous literature on online peer production (ranging from crowdsourcing to commons-based peer production as a more specific case), as well as works that have established and addressed the concept of "code as law" and the extent to which features of social and political governance can be inscribed in technology, contribute to defining the perimeter of our field of inquiry. Of particular importance is the recent body of work that addresses the decentralisation of networked architectures and infrastructures as a means of promoting or achieving specific values or normmaking processes. Finally, we examine precedent attempts at the systematization and categorization into typologies of complex procedures involving high levels of technicization and an articulate landscape of actors and their interactions.

\subsection{Online Peer-Production Platforms, from Crowdsourcing to the Commons}

The emergence of Web 2.0 and social media led to the development of platforms encouraging the creation and contribution of user-generated content, or production by peers defined as individual users ${ }^{5}$. Such platforms follow a wide variety of organizational models, oscillating

\footnotetext{
${ }^{5}$ We follow several of the authors cited in this section in adopting an admittedly broad definition of what constitutes "peer production", and as a consequence, of "peers", as individual users that are part of an online collaborative process of creation and contribution of content to/within a platform. This concept of peer does not only apply to commons-based peer production (as in, a more 'egalitarian' mode of production), but also to other forms of collaborative endeavours introduced in this section, such as for-profit or not-for-profit crowdsourcing. As detailed further below, such initiatives and platforms are indeed considered and studied as forms of "peer production", and this is why the more specific label of CBPP has been created to indicate those particular cases where hierarchy and concentration are absent, and which favour open licensing and reuse. As one of the core points of our typology is indeed to show that high levels of decentralisation in one or more of the dimensions can co-exist with
} 
between the so-called sharing economy, crowdsourcing or commons-based peer production, sometimes blurring the lines "between commodity and commons" (Meng and Wu, 2013). Platforms have frequently been recognized as embedding power relations by design (Mansell, 2015): Tarleton Gillespie underlines their capacity to act as "curators of public discourse" according to their technical features (2010), while José van Dijck acknowledges that "governance, ownership relations and business models" are structuring dynamics in the interplay of technologies, users and content on online platforms (2013).

Two research projects have been collecting data on peer-production platforms: in Europe the P2Pvalue project and its directory, which is itself crowdsourced, of 375 commons-based projects, ${ }^{6}$ and in the United States the Birds of the Internet team ${ }^{7}$, privileging the study of participation dynamics (Fish et al. 2011). Literature differentiates between several types of organization for peer production by online communities, depending on factors such as topdown coordination (crowdsourcing) or bottom-up self-organization (the commons).

On the one hand, platforms can reproduce the organization of a firm and manage the contributions of peers. This model corresponds to crowdsourcing: "the blend of bottom-up, open, creative process with top-down organizational goals" (Brabham 2008). One way to subcategorize crowdsourcing platforms where contributions are managed by a single coordinator is to distinguish between for-profit and non-profit crowdsourcing.

For-profit crowdsourcing generally favours the exploitation of digital workers (Mansell 2012: 58) and such phenomena as free labour (Terranova 2000), digital sweatshops (Scholz 2012), digital labour (Fuchs 2014) and turkers (Amazon Mechanical Turk ${ }^{8}$, for which Google Scholar ${ }^{9}$ provides more than 10,000 references) have been denounced. Critics cite the emerging social abuses prompted by the so-called "sharing" or "gift" economy organized by proprietary platforms, depriving workers of social rights (e.g. Über ${ }^{10}$, Taskrabbit $^{11}$ ).

Non-profit crowdsourcing also relies on free contributions, but, instead of enriching a company, it is meant to achieve for the common good tasks which would otherwise have required a massive investment. This is close to online volunteering (Cravens, 2014) as used in emergency situations (see Asmolov 2014, on Dobrovoletz.rf as vertical crowdsourcing), citizen science (see Madison, 2014, on GalaxyZoo ${ }^{12}$ ) or the work of GLAM (Galleries, Libraries, Archives and Museums) to preserve the digital heritage as a commons in partnership with Wikimedia chapters for the digitization of public domain works by Wikipedians ${ }^{13}$ (Dulong de Rosnay 2011).

On the other hand, online platforms can be used for commons-based peer production purposes, a "model of socio-economic production in which the labour of large numbers of people is coordinated (usually with the aid of the Internet) mostly without traditional hierarchical organization, often without financial direct remuneration" (Benkler 2006). Such collaboration will also aim at the common good, but without hierarchical central coordination, and with licensing mechanisms to prevent the private enclosure (Boyle 2003) of the peer production and allow its reuse (on open licensing and Creative Commons ${ }^{14}$ licensing, see Liang 2005; Bourcier and Dulong de Rosnay 2004). The most famous and widely studied example of peer production is Free, Libre and Open Source Software (Ghosh 2005; Schweik and English 2012; Kelty 2012) and the most famous peer-production platform is Wikipedia ${ }^{15}$ (Reagle 2010).

stronger centralisation of other dimensions, it seems important to us to retain this broad conceptualization of a peer, even if this is traditionally associated with symmetrical, egalitarian and distributed dynamics.

${ }^{6}$ P2Pvalue Directory of Commons Based Peer Production: http://directory.p2pvalue.eu/

7 The Birds of the Internet project: http://recursivepublic.net/

8 https://www.mturk.com/mturk/welcome

9 https://scholar.google.com/

${ }^{10}$ https://www.uber.com/

11 https://www.taskrabbit.com/

12 http://www.galaxyzoo.org/

13 https://outreach.wikimedia.org/wiki/GLAM

14 https://creativecommons.org/

15 https://www.wikipedia.org/ 
Peer-production platforms host the work of many other "online creation communities", defined as "collective action performed by a loosely integrated network of people that, cooperate, communicate and interact, mainly via the Internet, with the common goal of knowledgemaking, and engaged in alternative forms of knowledge management" (Fuster Morell, 2014a).

\subsection{Code is Law}

The relationship between architecture and norm-making for network-supported arrangements has been an increasingly central interdisciplinary preoccupation since the late 1990s/early 2000s. Early uses of the metaphor "code is law" can be found in William Mitchell's City of Bits (1995) and in Joel Reidenberg's article on lex informatica, the formation of information policy rules through technology (1998). However, legal scholars Yochai Benkler and Lawrence Lessig have arguably been the "scene-setters" in this field, with their work on sharing as a paradigm of economic production in its own right (2004) and technical architecture as politics (1999), respectively. While Benkler argues for the rise of a "networked information economy" as a system of "production, distribution, and consumption of information goods characterized by decentralised individual action carried out through widely distributed, nonmarket means" (Benkler 2006), Lessig introduces technical architecture as one of the four main (and interconnected) society regulators, the other three being law, market and norms. The application of this principle to the text of computer programs led to what remains, perhaps, the most striking incarnation of the famous "code is law" label (Lessig 1999).

Among the scholars who have since been inspired by this line of inquiry, Niva Elkin-Koren examines architecture as a dynamic parameter in the reciprocal influences of law and technology design within the field of information and communication systems (e.g. 2006, 2012). The interrelationship between law and technology often focuses on a single aspect, the challenges that emerging technologies pose to the existing legal regime, thereby creating a need for further legal reform; however, Elkin-Koren argues that juridical measures involving technology both as a target of regulation and as a means of enforcement should take into account the fact that the law does not merely respond to new technologies, but also shapes them and may affect their design (2006).

The work of Tim Wu adds layers to the conceptualization of the relationship between code and law, moving from Lessig's concept that computer code can substitute for law or other forms of regulation to consider code as an anti-regulatory mechanism or tool that certain groups will use to their advantage to minimize the costs of law-the possibility of "using code design as an alternative mechanism of interest group behavior" (Wu 2003).

\subsection{Technical (De)centralisation}

By conceptualizing network architectures as political, social and legal, certain authors have more specifically examined the ways in which the degree of centralisation, decentralisation and re-centralisation relate to innovation processes in the field of Internet services, platforms and networks. The current innovation trajectories of the network of networks, its evolutions and in-volutions, are likely to depend on the topology and organizational and technical models of Internet-based applications, and on the underlying infrastructure (Aigrain 2011).

The current model of organization of Internet platforms and of the structure of the network allowing these to function, with its obligatory points of passage, its more or less forced crossroads and its "toll roads", raises many questions about the optimal use of storage resources, bandwidth, computing capacity and about the fluidity, speed and efficiency of electronic exchanges, as well as the safety of these exchanges and the network's stability. These questions greatly influence the balance of power between network developers, users and operators, to the extent that they connect to issues surrounding the neutrality of the Internet (Schafer, Le Crosnier and Musiani 2011, 66-68). As Barbara van Schewick emphasizes, by influencing users' appropriations of the Internet-creating more or less openness, exchange and sharing-changes in the architecture of the network of networks influence its "social value" (van Schewick 2010). 
These characteristics can be studied from various angles, depending on how the underlying technical architecture is understood (Moglen 2010). Different types of architecture can influence, or provide alternative ways of addressing some critical issues surrounding the network's management, with a focus on efficiency, security, "sustainable digital development" through enhanced resource management, and the maximization of the Internet's value for society. Michel Bauwens (2005) has explored this idea further, proposing a vision of the P2P model based on its design as computer network technology, but recommending that $\mathrm{P} 2 \mathrm{P}$ underpin a "general theory" of collaborative and direct human interactions-an emerging, pervasive and social phenomenon that could profoundly influence how society and human civilization itself are organized.

\subsection{Typologies}

Processes of online norm-making, production and management become more and more complex: their governance is increasingly horizontal and multi-polar, the number of concerned actors multiplies, procedures become more participative and granular. Thus, it is hardly surprising that several authors have recently attempted not only to describe, but to systematize, categorize and "typify" the various socio-political and socio-technical dynamics that enable these processes, in order to advance a critical evaluation of their actual political significance and impact. These works have in common a priority of developing empirical and methodological tools enabling researchers to categorize the "reality" of theory and definitions related to a specific process. The focus remains on the procedural dimension in an attempt to interpret, compare and measure different entities that intervene in the process.

Dynamics related to and constitutive of peer production, such as online participation and digital labour, have been the subject of recent typology contributions that have sought to flesh out the different dimensions of online working conditions (Fuchs and Sandoval 2014), or of the "formal" social enterprises and "organized publics" involved in participation dynamics on the Internet (Fish et al. 2011). Due to the multi-faceted and distributed nature of the realm they are studying, Internet governance scholars have also engaged in several systematization efforts that provide useful methodological indications to develop our typology. Badouard et al. have developed a set of analytical categories and tools enabling a codification and comparative study of norm-production processes within the field of Internet governance, with the aim of analysing the different ways in which Internet governance actors address the challenge of multi-polarity by adapting their decision-making processes (Badouard et al. 2012). Related to their study is Archon Fung's work on patterns of participation in complex governance processes; his typology of deliberative processes is structured around three dimensions that are at once social, political and technical: the selection of participants, the communicative interactions between actors, and the assessment of authority "levels" among participants (Fung 2006).

While their subject matter is less closely related to the present study, useful methodological indications on typology-construction for complex processes can be drawn from Rudolf de Groot and colleagues' typology of the ecological and socio-economic value of goods and services provided by natural and semi-natural ecosystems (de Groot et al. 2002). Borgatti and Foster's typology of the different streams of the "network paradigm" in organizational research (Borgatti and Foster 2003), as well as Bell and Kozlowski's typology of virtual teams and its implications for effective leadership (Bell and Kozlowski 2002), are also useful because of their systematic analysis of clusters of individuals seeking to organize themselves in online environments.

\section{Methodology}

The core hypothesis underlying the present work is that the variety of organizational and procedural forms used within the peer-production realm (ownership and technical characteristics of the platform, the type of copyright agreement chosen to license its contents and the model 
of regulation implemented among its members) impact the results obtained and the types of norm constructed on the platform-ultimately, the quality of peer production. ${ }^{16}$.

Our units of analysis for the typology are "online peer-production platforms", which we define as integrated, web-based platforms that support online collaboration, resulting in online or offline peer production or crowdsourcing. Through this methodological choice we wish to reinforce our core objective of addressing peer-production arrangements by taking into account their underlying technical dimensions and their political/legal components, both of which we consider crucial to producing a comprehensive typology.

Peer-production platforms generally foster claims of self-organization, community values and shared objectives, although, as we demonstrate, these take shape in a variety of forms. For the purpose of this paper, we do not investigate the possible gap between these claims and their implementation in practice; as such, an investigation would require in-depth, qualitative case studies of the different platforms. ${ }^{17}$ Thus, our analysis relies almost exclusively on the documents produced by the developers, owners, and users of the platforms and to be found online (terms of use, privacy policies, "charts" outlining the rights and obligations of users, release notes of the different technical versions of the platforms). It also draws upon observation and engagement with the techno-social systems, in particular with their interfaces, to the extent that these shape governance as much as do written documents.

The construction of the typology involved several steps. While it seemed clear that the core question structuring our work would be the extent of (de)centralisation, the first attempt to draw the present typology included two dimensions: the technical design of the underlying architecture and the system of governance (i.e. the social organization regulating the interactions between community members), including the system of ownership of production. This led to four possible ideal types (presented in Dulong de Rosnay 2013a):

\begin{tabular}{|c|c|c|}
\hline & Centralised architecture & Decentralised architecture \\
\hline Centralised governance & Facebook & Skype \\
\hline Decentralised governance & Wikipedia & Diaspora \\
\hline
\end{tabular}

Table 1: Towards ideal types crossing governance and technology

A further investigation of the relevant literature as well as the properties of various online platforms, employed by different peer-production communities, led us to distinguish additional dimensions: the rights-vesting of the means of production and the value of the output. The central question about the level of (de)centralisation is articulated in the following research questions:

- To what extent is the ownership of the platform (understood as a means of production) centralised or decentralised-ranging from exclusive ownership concentrated in

\footnotetext{
${ }^{16}$ A related hypothesis is that in turn, the shape taken by these results affects subsequent reconfigurations of technical architecture, ownership agreements, governance models and value distribution; however, as this is not a primarily empirical paper, we will not test it here.

${ }^{17}$ In the instances where such case studies exist, we refer to the literature cited in the previous sections. However, we do not try to draw normative indications, for example, from the successes or failures of specific projects "in practice", or the extent to which their conduct may be more or less accurately mirrored in their stated organizational model. Although we acknowledge, as we will further note in the conclusions, that case studies are and will be a necessary complement to the present study.
} 
the hands of one or more platform owner(s) to more distributed or cooperative ownership?

- To what extent is the technical infrastructure centralised or decentralised-ranging from a high level of centralisation around one or more server(s) to more decentralised and distributed models, spread out among several nodes or peers?

- To what extent is the governance model centralised or decentralised-ranging from hierarchical organizations with centralised powers and delegated decision-making to more grassroots models based on bottom-up structures and distributed process of participation?

- To what extent is the copyright regime of the peer-production output centralised or decentralised-ranging from exclusive terms of use, where users have to grant ownership of the output to the platform owner, to more distributed legal models implemented via copyleft licences?

- To what extent is the value generated from the peer production centralised or decentralised-ranging from exclusive appropriation of the economic benefits by the platform owner(s) to redistribution of social benefits, also non market-based, to the community or to society at large?

The examples selected to illustrate the different ideal types structuring the typology have been chosen according to the diversity between them and thus the extent to which their features (purpose of platform, types of content produced, actors involved in peer production process) may be found in, or assimilated to, similar features in other platforms. In some cases it has proved effective to select "famous" platforms, such as Wikipedia, because of the amount of information available on these.

\section{The Typology}

Figure 2 presents the analytical framework that will be detailed in the following sections. This table reflects the various types of peer-production platform that can be achieved from a combination of different ownership arrangements, architectural designs, governance structures, rights ownership and value distribution. It should be noted, however, that these models reflect tendencies rather than pure cases, and that more granular levels of centralisation/decentralisation could be distinguished within each category. In other words, the answers to the five research questions above should, for most peer-production platforms, be understood as placed on continuums that, for each level of analysis, display a more or less important level of (de)centralisation. Nonetheless, for the construction of ideal types, we use examples that mostly sit at the extremes of the continuums. 


\begin{tabular}{|c|c|c|c|c|c|}
\hline \multirow{1}{*}{ Centralised } & Ownership & Technology & Governance & Rights & Value \\
\hline $\begin{array}{c}\text { Major plat- } \\
\text { forms }\end{array}$ & $\begin{array}{c}\text { Contral server } \\
\text { platform owner }\end{array}$ & $\begin{array}{c}\text { Top-down } \\
\text { decision- } \\
\text { making by } \\
\text { platform own- } \\
\text { er }\end{array}$ & $\begin{array}{c}\text { Exclusive } \\
\text { rights as- } \\
\text { signed to plat- } \\
\text { form owner }\end{array}$ & $\begin{array}{c}\text { Concentrated } \\
\text { in hands of } \\
\text { platform own- } \\
\text { er }\end{array}$ \\
\hline Decentral- \\
ised
\end{tabular}

Table 2: A typology of peer-production platforms based on (de)centralisation

\section{The five dimensions}

This section presents the core elements of the typology, analyzing how the (de)centralisation criterion can be applied to each of the five selected dimensions: ownership of means of production (Section 5.1), technical architecture (Section 5.2), governance (Section 5.3), ownership of production output (Section 5.4) and value-generation (Section 5.5). Examples follow the definition and discussion, in order to illustrate the arguments with concrete cases.

\subsection{Ownership of the Means of Production}

The platform's online means of production are its creative and networking interface as well as its distribution, storage and processing capabilities. Ownership of these can be centralised in the hands of a firm or a non-profit entity, which controls the brand, the patent, the quality. It can also be distributed among contributors structured in the semi-centralised format of a cooperative, a cloud of local networks, or informal networks where each peer or node owns and control its own servers.

A previous typology of digital media labour distinguishes among three modes of organization of productive forces (Fuchs and Sandoval 2014): ownership of labour power, of the means of production, and of work output; with various degrees of control, from centralised to decentralised: self-control, partial self-control and partial "alien" (or external) control, full alien control.

In the vocabulary of the commons, the ownership of the means of production corresponds to the provision of infrastructure: this is the dimension that, according to Ostrom's Institutional Analysis Framework (1990), allows work to be performed. The concept of infrastructure traditionally includes the means of transportation (roads) or communication (telecommunications networks) and has been extended to ideas: the intellectual or cultural infrastructure (Frischmann 2013). The concept of infrastructure provision has been applied to online creation 
communities in order to study their governance and the building of a digital commons (Fuster Morell 2014b).

The concentration of ownership of the means of production will have an impact on the other dimensions. In a Marxist sense, "The first form of alienation refers to the product of the worker's own work and the inability to use the product of this own work for his or her living. The second form of alienation refers to the inability to organise the process of work, which lies exclusively in the hands of the capitalist who owns the means of production" (Wittel 2012). While it is evident that free labour is leveraged when a user-generated content platform is exploited by capital, no conclusion can be drawn in the case of distributed ownership.

Ownership of the platform can be centralised in the hands of a single firm or stockholders (e.g. Flickr ${ }^{18}$, Facebook ${ }^{19}$ ). It can also be centralised in the hands of a non-profit entity (e.g. the Wikimedia Foundation, ${ }^{20}$ or Creative Commons in the case of a legal infrastructure controlling the licensing offer), which controls the peer-production brand. In the latter case, the trademark is not managed according to commons-based principles, but controlled following a strict intellectual property policy.

There can also be decentralised or federated ownership of a platform among informal networks, where each node owns and controls its own servers (e.g. Identi.ca ${ }^{21}$, Diaspora ${ }^{* 22}$ ), allowing, for instance, the removal of inappropriate or infringing content. This usually involves a strong technical component, which will be addressed in the next section.

At this stage of our analysis, we cannot draw a conclusion as to whether contributors are able to benefit more from their work (or to be less excluded from enjoying the benefits of their production) if the platform is owned by a non-profit, or if it is not owned at all. Neither can we assert that more centralisation of platform ownership will lead to more exploitation of contributors. Both the market (if the entity is capitalistic) and commons-based peer production (if the platform is non-profit) rely on free labour. The same platform can even switch its status from non-profit to corporation (e.g. Couchsurfing ${ }^{23}$; see Schöpf 2015). The question of the ownership of the contributions produced and the sharing of the generated value is addressed in subsequent sections.

\subsection{Technical Architecture}

To define our second dimension, technical architecture, we borrow from the IEEE Standard for Architectural Description of Software-Intensive Systems (IEEE P1471/D5.3), which describes it as "the fundamental organization of a system embodied by its components, their relationships to each other and to the environment and the principles guiding its design and evolution" (Bredemayer and Malan 2001).

Thus, the architecture of a network or an application is its underlying technical structure (van Schewick 2010), designed according to a "matrix of concepts" (Agre 2003): its logical and structural layout, consisting of transmission equipment, communication protocols, infrastructure, and connectivity between its components or nodes. It is increasingly recognized that changes, notably design choices, in the Internet's architecture affect the economic environment for innovation, and in turn impact public policy. While policy-makers have traditionally used the law to bring about desired economic effects, architecture de facto constitutes an alternative way of influencing economic systems and as such is becoming another tool that actors can use to further their own interests (van Schewick 2010).

The design of peer-production platforms can be organized according to a centralised architecture, around servers hosted locally or in the cloud, and can give the administrator full control and power of exclusion over production, contributors and output. Centralisation can subsist at several layers of the infrastructure, the most obvious being the servers on which

\footnotetext{
${ }^{18} \mathrm{https://www.flickr.com/}$

19 https://www.facebook.com/

20 https://wikimediafoundation.org/

21 https://identi.ca/

22 https://joindiaspora.com/

23 https://www.couchsurfing.com/
} 
the applications are running and the content produced is hosted (e.g. Facebook). Other (less centralised) models may include a limited number of (super-)nodes responsible for controlling and administering the production platform (e.g. Skype ${ }^{24}$ ). Generally, the greater the degree of centralisation, the higher will be the degree of control given to the administrator over the process and output of production. Architectures with a centralised system of governance facilitate the coordination of individuals contributing to collaborative work and are generally easier to implement technically than the decentralised alternatives (for propositions to resolve these difficulties, see Antoniadis and Le Grand 2009). Centralised platforms based on proprietary software and single points of control at the technical level are, however, more likely to facilitate privatization and concentration (with the possible facilitation of abuse of dominant positions that this entails).

At the other end of the spectrum, technical architecture can also be distributed among peers (Musiani 2015). This is the case for many peer-to-peer networks that rely on the willingness of multiple users to share their own resources (e.g. BitTorrent ${ }^{25}$ for file-sharing, Diaspora* for social networking) so as to contribute to the proper functioning of the network or application $^{26}$. This is also the case for mesh networking applications (e.g. Commotion ${ }^{27}$ ) that rely on the technical infrastructures of users' devices to provide resources and wireless connectivity to the other users of the network (Antoniadis and Le Grand 2009). Unlike centralised models, these architectures considerably enhance the autonomy of users; however, by sharing capabilities and responsibilities and fragmenting actions and files, decentralised architectures make it more difficult for an entity, be it a firm, a collective, an individual or the state, to enforce control (Guadamuz 2011; Dulong de Rosnay 2015).

\subsection{Governance}

The scholarly debate on what constitutes governance of socio-technical systems, how its boundaries should be drawn, and what actors are involved is currently wide-ranging and complex (Borras and Edler 2014). For the purpose of this paper and its typology, we define governance as the set of decision-making processes, the ensemble of procedures that frame production, the process of work, and the choices subtending the organizational design of peer-production platforms, including technical, legal and value-sharing choices. Depending on their degree of (de)centralisation, these features can contribute to the empowerment of peer producers and the distribution of the tasks conducted on the platform.

Intended in this connotation, the governance of peer production has been addressed in several contributions. As in the present study, Aaron Shaw (2013) uses the parameter of decentralisation to assess how relational governance mechanisms, such as gatekeeping, play a role within open online collectives in managing organizational boundaries and filtering the contributions of participants; concluding with regard to the existence of a mix of centralised and decentralised gatekeeping, he observes that the egalitarian ethos of open online collectives exists in tension with the mechanisms through which participation and status inequalities emerge among participants. In collaboration with Benjamin Mako Hill, Shaw further observes that governance in peer production may actually, and counter-intuitively, tend towards concentration ("oligarchy") as projects grow (Shaw and Hill 2014). Building on previous work on the governance of participation (Fish et al. 2011), Currie et al. (2013) apply notions such as Hirschman's "exit, voice and loyalty" in their definition of governance in peerproduction projects (using the case of free software). They argue that this definition needs to include the answer to questions such as: "Is there a formal procedure for decision-making? If not, how are decisions made? Do participants have the capacity to exercise both exit (without penalty) and voice (without fear of reprimand)? [...] What constitutes having a real voice, and how does it manifest in discussion forums, face-to-face meetings, and financial dona-

\footnotetext{
${ }^{24}$ http://www.skype.com/

25 http://www.bittorrent.com/

${ }^{26}$ A related case, presenting a peculiar dynamic of technical delegation, distributed labor and re-centralisation, is that of distributed computing platforms such as SETI@home, an early form of crowdsourcing that harnessed idle computing cycles of users' computers to subsequently re-centralize the results of such computing tasks.

${ }^{27} \mathrm{https}$ ://commotionwireless.net/
} 
tions? Can participants leave without losing something, or protest and expect to be heard? What can you not exit from, such as formal or technical commitments to a website, a platform, an account, etc.?" (Currie et al. 2013).

The (de)centralisation parameter at the core of our typology can be applied to the four elements of our operational definition of governance: terms of use, production rules, work process and design choices. These are examined briefly and examples provided.

Terms of use can be unilaterally imposed by the entity operating the platform (e.g. Flickr), or they can be drafted collectively or otherwise negotiated among peers in the case of selfmanaged projects (e.g. Lorea ${ }^{28}$ ). In the former case, users do not have any influence on the governance of the platform; if they want to use the service, they necessarily have to accept and comply with the terms and conditions. The latter case represents, instead, an example of distributed, commons-based governance; in this case, peers not only have their say in the terms of use, but also have the opportunity to participate in establishing the rules of production. In this regard, different degrees of decentralisation may range from the opportunity to comment or vote ${ }^{29}$ on licensing changes (e.g. Facebook) to the possibility of engaging in a real collaborative drafting process (e.g. Wikipedia; see Forte, Larco and Bruckman 2009). Wikipedia is a case of governance being semi-distributed among several nodes structured in semi-centralised clusters (administrators and editors control what is accepted or rejected in case of conflict) or decentralised local networks (chapters for choosing projects and thematics on which to focus, e.g. the Wikicheese ${ }^{30}$ project of Wikimedia France).

Beyond the drafting of rules which users have to respect in order to participate in the peerproduction process, governance is also embedded in the work process and the organizational design. Distributed organizational design of product development can take place in innovative firms, which apply self-governance $\left(V^{2} / v^{31}\right)$. More fully distributed governance models will be based on decentralised decision-making and cooperative management. As opposed to traditional systems of governance based on hierarchical and centralised decision-making, distributed governance models are often more empowering to contributors and users. They are based on bottom-up, decentralised processes of decision-making and generally exist in innovative firms or communities, which rely on self-governance and cooperative management. Even companies with centralised ownership can embrace distributed management (e.g. Valve; see van der Graaf 2012).

Finally, the governance of the design choices of the platform itself can be subjected to more or less centralised control. This will move towards more distribution of power if users have the capacity to propose new features to be integrated into the service. It will go further if they can develop such features themselves, in the form of plug-ins or add-ons. If the technology is based on Free/Libre Open Source Software (FLOSS), this feature will reach the fullest level of decentralisation and enable exit without penalty, by means of forking to create a new, parallel project duplicating previous contributions and starting afresh. Decentralised governance is here supported by, and embedded in, the openness of the technical design based on the software and data licensing, empowering peers to modify the platform, adapt it to their needs and transfer the datasets. Inversely, if the technology is closed, a central point of control will be re-introduced in order to validate the new feature (e.g. AppStore ${ }^{32}$ ).

\subsection{Ownership of Peer Production Output}

From texts and photos to comments and editing, most creative contributions on peer platforms are subject to copyright law. By ownership of peer production output, we mean the large scope of copyright licensing arrangements, which may be present in the platform's Terms of Use, governing the use and reuse conditions of the content created by users. A

\footnotetext{
${ }^{28}$ http://lorea.org/

${ }^{29}$ As a reminder (see Section 3), the purpose of this paper is not to investigate the intrinsic quality of processes such as Facebook's voting procedure, or to investigate the possible gap between these claims and their implementation in practice, as this would require in-depth, qualitative case studies of the different platforms.

${ }^{30} \mathrm{https}$ ://fr.wikipedia.org/wiki/Wikip\%C3\%A9dia:WikiCheese

31 http://www.valvesoftware.com/

32 https://itunes.apple.com/pw/genre/ios/id36?mt=8
} 
synonym for this is availability: according to the typology of Currie et al. (2013), "from GNU General Public License to Creative Commons licenses to moral economies where no formal legal structure exists, to direct corporate expropriation, where participants knowingly carry out free or underpaid labour and indirect expropriation, as when participants often unwittingly offer up their data for commercial usage". These conditions of appropriation of the fruits of creative (in the copyright sense) labour performed by peers can be a direct consequence of features such as ownership of means of production and governance of terms of use. If a platform is centrally owned and governed, terms of use can be and will probably have been drafted by the corporation or the non-profit. Distributed governance gives users a chance to obtain more favourable licensing choices even if Terms of Use cannot generally be negotiated and have to be accepted in order to contribute on the platform.

The scope of licensing options, the bundle of rights ${ }^{33}$ according to our typology oscillates between the highest and exclusive concentration of rights in the hands of the platform's owner (thus, centralisation ${ }^{34}$ ) and their widest redistribution and availability for others (hence, decentralisation). It will have an impact on the value of the output generated (as we analyse in the next section), depending on the gradation in sharing of rights between the platform, the original user-contributor and subsequent users in the audience who may become contributors and may build upon the peer production. A few notable examples (e.g. Facebook) show that terms of use endowing the platform owner with the highest degree of concentration favour a high level of concentration in platform ownership and rights ownership.

The platform can assert exclusivity over peer production through Terms of Use governing users' contributions. Contributors accepting the transfer of all rights and granting full exclusivity to a platform will not be able to reuse their contribution on another platform. Social media often require a full transfer for the exploitation of fan fiction (Ford 2015): Amazon Kindle Worlds ${ }^{35}$, although offering royalties to contributors, requires that "When you submit your story in a World, you are granting Amazon Publishing an exclusive license to the story and all the original elements you include in that story".

Some platforms relying on user participation, even if they are owned by commercial companies, may allow modifications to be freely available in order to increase further traffic and reuse, and thereby purchases, donations or grants, leading to new forms of value-sharing (in the context of "mods", modified video games, see van der Graaf 2012).

Instead of a transfer of ownership away from the creator, the platform can require a nonexclusive licence that allows it to reuse content, sell, transfer or sub-license content, or to use it in conjunction with advertising (Instagram ${ }^{36}$ or Second Life ${ }^{37}$ ).

The platform can claim a non-exclusive licence, but only to display the content, thereby allowing the system to function a minima, without extending the license to the right to sell (Twitter ${ }^{38}$ also corresponds to that standard).

If information is absent, if no terms of use or licence are specified, copyright will apply by default and all rights will remain with the author; only the use of a Creative Commons or similar licence would define the scope of third-party permissions (Kopfschlag ${ }^{39}$ ).

As is the case, for example, with Creative Commons licences, ${ }^{40}$ the range of options used among free culture and digital commons communities includes different ways of the creator retaining some rights (more centralisation) while sharing some rights over peer production

\footnotetext{
${ }^{33}$ Copyright grants a bundle of rights to creators, which can then be licensed, assigned or further transferred, exclusively or not. Ostrom's bundle of rights is different since it does not apply specifically to untangible works. A fundamental notion in common law, it is also a basic of civil law (usus, fructus and abusus).

${ }^{34}$ We do not address the specific situation of rights assignment to the Free Software Foundation just for the purpose of their enforcement

35 https://kindleworlds.amazon.com/

36 https://instagram.com/

37 http://secondlife.com/

38 https://twitter.com/

39 http://www.kopfschlag.com/

${ }^{40}$ Rights remaining with the public are non-commercial usage (with CC ND NC), usage and the right to make

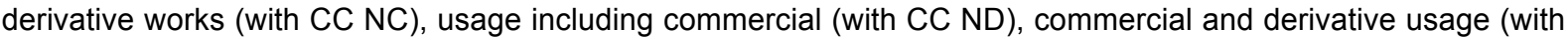
CC BY).
} 
with the public (more decentralisation). All Creative Commons licenses options guarantee the right of access to all (usus), the right of modification or commercialization (fructus) may be performed by others according to creators' permissions, who can prevent exclusion or enclosure (abusus) with a copyleft, share-alike clause.

Reserving rights to commercial exploitation will partially recentralize ownership, to the extent that the author becomes a central contact point for commercial exploitation.

Reserving derivative rights only will partially decentralize the commercial exploitation of the original production.

The copyleft option provides a distributed, shared ownership and prevents further recentralisation (or enclosure) of the production's derivatives. The latter regime requires modifications (fructus) to be licensed according to the same conditions of access and use (usus and abusus), thus distributing ownership by granting rights to the public, which members may use by creating a derivative.

The attribution option and public domain dedication will fully distribute the rights' exercise, allowing anyone even to re-proprietize a derivative of the peer production.

\subsection{Value}

Our fifth dimension addresses the value of the output of the peer-production process. While we acknowledge that defining value as it relates to peer production is a process in the making, and still incomplete ${ }^{41}$, we define value operationally, for the purpose of this typology, as the management of benefits, understood as both market-based economic and unquantifiable socio-cultural benefits, generated from the peer-production process, ranging from their exclusive appropriation by an actor or a group of actors (most often the owner of the platform), to redistribution to the community and even further, to society at large (thus, according to our typology, at the further end of the decentralisation spectrum).

Value is heavily linked to ownership of the means of production and of the peer production itself; in this regard, Currie et al. (2013) wonder: "Is there collective control and/or individual access to the resource produced by participation? Can participants trust that what they give to a project will be returned to them in some form (credit and authorship, legal rights, access to resources)?"

We build this definition on the number of recent contributions in which value in commonsbased peer production has been tentatively defined. Coleman (2005)'s notion of "ethical labour", Kelty (2008)'s analysis of "schooling", Arvidsson and Peitersen (2013)'s contribution on "reputation" focus on the production work more than on the production output.

Value assessment of public domain works (Pollock 2006; Erickson et al. 2015), which digitization and preservation can be achieved through peer production (Dulong de Rosnay 2013a), and which reuse will lead to further peer production, can serve as a useful analogy. Evaluation models developed by Pollock and Erickson et al. are powerful, but still marketbased. In a broader definition of value, we want to take into account not only the commercial exploitation of the production (or its equivalent) and the social value of cooperation for the peers, but also include non-quantifiable cultural benefits. Capital-based metrics are unable to take into account the quality cultural value of peer production. Happiness metrics are also market-based, and demonstrating the political value of the commons and of sharing will require a conceptual framework, which will depart from capital-like evaluation of the public domain, open data or reputational economies. Net value, compensated value, creation costs, business models, economic opportunities for investors, commercial equivalent, cost savings, visitorship are useful indicators in Pollock and Erickson et al. Personal benefits for the producer, and advantages for the user, have been studied for free software. But there are no metrics to appreciate the advantages and "pleasure" for society derived from production and access to works and services of quality, towards intangible cultural collective development and not only economic development.

\footnotetext{
${ }^{41}$ According to Arvidsson and Peitersen $(2013,84)$, CBPP theorists Benkler and Bauwens both avoid the question of value creation, for ideological, idealistic reasons
} 
Fuster Morell et al. (2014) argue that the question of value in collaborative communities is a matter of both economy and justice, as "[t]he problem of how to regulate and reward activities that are presently without a market value [...] is contingent [upon finding] a rational and transparent measure of value", and build a definition of value in peer production that includes six dimensions: community building (dimension of the community/network of producers), objective accomplishment, monetary value, reputation, ecological value and social use value of the resulting resource.

Building upon Bauwens' seminal work on the political economy of peer production (2005), Tkacz, Mendoza and Musiani (2014) also highlight the role of peer-production processes in producing "bearable hierarchies", and in turn how these are crucial in defining value, observing how "the intensification and extension of computational processes [...] has led to a proliferation of bottom-up procedures to formalise (social) values, rendering them easily calculable and lending order to the decentralised world of peers, but without necessarily replicating capitalistic calculations of value"; if hierarchies persist in peer production, they point out, "perhaps it is the qualities of these new hierarchies and competitive forms that is novel". This ties into Bechmann and Lomborg's (2012) observation that value creation in social media is either addressed in economic and socio-political terms (power, exploitation and business revenues) or as "sense-making", creative explorations of the self and management of social relationships; the authors argue that these different conceptions of value creation have consequences when it comes to conceptualize users as participatory agents-as peers in the sense adopted in this article.

More specifically on the quality and the reusability of CBPP (and user-generated content distributed under open licenses at large), Dulong de Rosnay (2013b) introduces the impact of the legal framework (besides copyright licensing) on value in peer production, as the provision or disclaimer of liability for peer-production outputs will have an impact on the motivations of contributors and on the possibility to add value to the output of others by creating derivative works, as one of the motto of free culture is to build upon previous works: large amounts of open content, without a representation by the licensor that this is not infringing upon others' rights - a frequent output of peer production-cannot be safely reused and do not necessarily entail good value in the long term. If copyleft licensing potentially multiplies the value of the production, as it allows its transformation, the absence of warranty that it can be safely and legally done hampers the economic value, as authors or derivatives may face legal risks. It also potentially diminishes the social value of the commons if cooperation is discouraged. Quantitative measurement of Creative Commons licensed works is achievable $^{42}$, but measurement of derivatives from Creative Commons licensed works has not been performed.

Along these lines, Kreiss, Finn and Turner (2011) note that, in peer production, changes in ubiquity and power relations at the level of processes do not necessarily imply a revolution in the attribution of benefits related to outputs. Kostakis (2013), building on previous work on the "crisis of value", points out the sustainability problem when assessing value in peer production: he remarks that more and more of commons-based peer producers' time goes into producing use value (utility as valuable to someone), but there is no substantial return of income to them: a volunteer pool can be sustainable collectively through the continuous renewal of its members, but membership cannot be exclusively composed of volunteer individuals on a permanent basis.

In its variety of for-profit forms, the so-called sharing economy is an example of how value in peer production is often (re)centralised in the same way it was analyzed by Terranova (2000). Several businesses in the sharing economy, such as Über and Airbnb ${ }^{43}$, can arguably be considered as a deviation from the symmetrical, egalitarian, (perhaps utopian), collaboration-based model of the original idea of carpooling and couchsurfing, reducing or voiding some of the traditional costs associated with doing business by delegating tasks to users and co-opting their output, and concentrating the benefits derived from this. In this sense, "peer

\footnotetext{
${ }^{42}$ https://stateof.creativecommons.org/2015/

43 https://www.airbnb.com/
} 
labour seems to both depend on, and, at times, extend existing concentrations of resources" (Kreiss et al. 2011, 255).

At the other end of the spectrum, emerging legal instruments such as copyfarleft licences (Kleiner 2007) can be leveraged to decentralize value in peer-production processes, as they "distinguish between commercial usages enacted by worker-owned collectives, cooperatives, or any other institution where profits are distributed (equally) amongst all workers, and those enacted by commercial entities or corporations whose businesses are exclusively based on the exploitation of wage labour" (Vieira and De Filippi 2014). Copyfarleft and reciprocity principles are emerging, and licensing schemes are still under development at the time of writing; therefore, there is no practical example of an application embedding these principles of value redistribution.

\section{Conclusions}

This article has presented a typology of five different features in online peer-production platforms: ownership of the means of production, technical architecture, copyright ownership of the production output, governance arrangements, and redistribution of the value generated by the platform. The typology has adopted (de)centralisation as the cross-cutting criterion of analysis for these features.

Our objective throughout has not been primarily normative, but rather one of description and analysis - and these conclusions are no exception. We do not wish to suggest that there is a mix of "ideal" levels of decentralisation that these five features can achieve in order to build, in turn, an "ideal" peer-production platform. There can be no such thing in a realm that-as this article and many others have shown in recent years-is populated by so many different actors, aims, objectives, products and processes. However, this typology can hopefully constitute a systematic critical perspective on the different layers of peer-production design-a comprehensive reference of categories, continuums and ideal types, enabling platform developers, users, regulators (and researchers) to delve into which parameters may facilitate or impede dynamics tending towards profit and exclusion or, on the contrary, collective governance of commons-based peer production and redistribution of value. The typology also draws attention on the need to frame peer production and its theories of value outside of a market-based evaluation of both the process and the output, and to appreciate unquantifiable, collective social and cultural benefits. Beyond acting as an analytical contribution to the scientific framing of the field, the typology aims at breaking down and exposing the political benefits of decentralisation for specific peer production dynamics.

Today, communities of both research and practice are giving their full attention to concepts such as the sharing economy, participation, collaboration, the commons, and the dynamics that these subtend-while at the same time struggling ethically and methodologically with a number of implications, including overtime sustainability, hype vs. disillusionment, gaps between manifestos, realities, and political values. With our typology, we have also wished to contribute to the untangling of these complex issues within a field of research and practice that is increasingly rich and articulated. Just as it holds opportunities-brought to the fore by a predominantly participatory and emancipatory discourse-peer production also has its limits, as Kreiss et al. (2011) remind us. Tools such as this typology may help to underline the extent to which opportunities and limits are embedded in a variety of layers and levels of the peer-production process-and how the very concepts of "opportunity" and "limit" in peer production are relative, depending on the actors and the objectives involved in the process. It is up to future research to bring further nuances to the mosaic, by means of further systematization attempts as well as further detailed case studies that will shed light on what this typology has deliberately not addressed: the gap between claims to participation and equality, and their day-to-day implementation in practice.

\section{References}

All links last accessed November 11, 2015. 
Agre, Philip. 2003. Peer-to-Peer and the Promise of Internet Equality. Communications of the ACM 46 (2): 39-42. http://polaris.gseis.ucla.edu/pagre/peer.html.

Aigrain, Philippe. 2011. Declouding Freedom: Reclaiming Servers, Services and Data. In 2020 FLOSS Roadmap (2010 Version/3rd Edition). https://www.flossroadmap.coment.com/text/NUFVxf6wwK2/view/.

Antoniadis Panayotis, Le Grand Bénédicte. 2009. Self-organised virtual communities: bridging the gap between web-based communities and P2P systems. International Journal of Web Based Communities 5 (2): 179-194.

http://www.tik.ee.ethz.ch/ pantonia/papers/2009.IJWBC.p2p_social_incentives draft.pdf.

Asmolov, Gregory. 2014, Vertical crowdsourcing: The discourses of activity and the governance of crowds in emergency situations. Proceeding of the Internet, Policy and Politics conference. Oxford Internet Institute. http://ipp.oii.ox.ac.uk/sites/ipp/files/documents/IPP2014_Asmolov.pdf.

Badouard, Romain, Francesca Musiani, Cécile Méadel and Laurence Monnoyer-Smith. 2012. Towards a Typology of Internet Governance Socio-Technical Arrangements. In Normative Experience in Internet Politics, edited by Françoise Massit-Folléa, Cécile Méadel and Laurence MonnoyerSmith, 99-124. Paris: Presses de l'Ecole des Mines. http://books.openedition.org/pressesmines/586?lang=fr.

Bauwens, Michel. 2005. The Political Economy of Peer Production. CTheory 1. http://www.ctheory.net/articles.aspx?id=499.

Bechmann, Anja and Lomborg, Stine. 2013. Mapping Actor Roles in Social Media: Different Perspectives on Value Creation in Theories of User Participation. New Media and Society 15 (5): 765-781.

Bell, Susan. 2002. Economic Governance and Institutional Dynamics. Melbourne, Australia: Oxford University Press.

Benkler, Yochai. 2004. Sharing Nicely: On Shareable Goods and the Emergence of Sharing as a Modality of Economic Production. The Yale Law Journal 114 (2): 273-358. http://benkler.org/SharingNicely.html.

Benkler, Yochai. 2006. The Wealth of Networks: How Social Production Transforms Markets and Freedom. New Haven, CT: Yale University Press. http://www.benkler.org/Benkler_Wealth_Of_Networks.pdf.

Borgatti, Stephen and Pacey Foster. 2003. The Network Paradigm in Organizational Research: A Review and Typology. Journal of Management 29 (6): 991-1013.

http://www.analytictech.com/borgatti/papers/borgattifoster.pdf.

Borras, Susana and Jacob Edler. 2014. The Governance of Socio-Technical Systems. Edward Elgar Publishing.

Botsman, Rachel. 2013. The Sharing Economy Lacks of a Shared Definition. CoExist. http://www.fastcoexist.com/3022028/the-sharing-economy-lacks-a-shared-definition.

Bourcier, Danièle and Melanie Dulong de Rosnay (eds.). 2004. International Commons at the Digital Age_La création en partage. Romillat. https://hal.archives-ouvertes.fr/hal-00666304.

Boyle, James. 2003. The Second Enclosure Movement and the Construction of the Public Domain. Law and Contemporary Problems 66: 33-74. http://scholarship.law.duke.edu/lcp/vol66/iss1/2/.

Brabham, Daren C. 2008. Crowdsourcing as a Model for Problem Solving an Introduction and Cases. Convergence 14(1): 75-90. http://www.crowdsourcingverband.de/wpcontent/uploads/2013/01/Brabham_Crowdsourcing_Problem_Solving.pdf.

Bredemayer, Dana and Ruth Malan. 2001. Architecture Definitions.

http://www.bredemeyer.com/pdf files/Definitions.pdf.

Coleman, E. Gabriella. 2005. Three Ethical Moments in Debian. http://ssrn.com/abstract $=805287$.

Cravens, Jayne. 2014. Internet-mediated Volunteering in the EU. European Commission Joint Research Centre Institute for Prospective Technological Studies. Luxembourg: Publications Office of the European Union. http://ftp.jrc.es/EURdoc/JRC85755.pdf.

Currie, Morgan, Christopher Kelty and Luis Felipe Rosado Murillo. 2013. Free Software Trajectories: From Organized Publics to Formal Social Enterprises? Journal of Peer Production 1 (3). http://peerproduction.net/issues/issue-3-free-software-epistemics/peer-reviewed-papers/freesoftware-trajectories-from-organized-publics-to-formal-social-enterprises/.

de Groot, Rudolf, Matthew Wilson and Roelof Boumans. 2002. A Typology for the Classification, Description and Valuation of Ecosystem Functions, Goods and Services. Ecological Economics 41 (3): 393-408.

Dulong de Rosnay, Melanie. 2011. Access to Digital Collections of Public Domain Works: Enclosure of the Commons Managed by Libraries and Museums. 13th Biennial Conference of the International 
Association for the Study of the Commons (IASC). https://halshs.archives-ouvertes.fr/halshs00671628.

Dulong de Rosnay, Melanie. 2013a. Peer-Production Online Communities Infrastructures. ACM Proceedings of the First Conference on Internet Science. Brussels, Belgium, 10-11 April, 65-68. https://hal.archives-ouvertes.fr/hal-00833476.

Dulong de Rosnay, Melanie. 2013b. Open Content Licenses Without Representation: Can You Give Away More Rights Than You Have? European Journal of Law and Technology (EJLT) 4 (3). https://halshs.archives-ouvertes.fr/halshs-00921618.

Dulong de Rosnay, Melanie. 2015. Peer-to-Peer as a Design Principle for Law: Distribute the Law, Journal of Peer Production 6. Special issue on Peer Production, Disruption and the Law. http://peerproduction.net/issues/issue-6-disruption-and-the-law/peer-reviewed-articles/peer-to-peeras-a-design-principle-for-law-distribute-the-law/.

Elkin-Koren, Niva. 2006. Making Technology Visible: Liability of Internet Service Providers for Peer-toPeer Traffic. New York University Journal of Legislation and Public Policy, 9 (15), 15-76. http://www.nyujlpp.org/wp-content/uploads/2012/11/Niva-Elkin-Koren-Making-TechnologyVisible.pdf

Elkin-Koren, Niva. 2012. Governing Access to User-Generated Content: The Changing Nature of Private Ordering in Digital Networks. In Brousseau, Eric, Marzouki, Meryem, Méadel, Cécile. (eds.), Governance, Regulations and Powers on the Internet, Cambridge: Cambridge University Press. http://papers.ssrn.com/sol3/papers.cfm?abstract id=1321164

Erickson, Kris, Heald, Paul J., Homberg, Fabian, Kretschmer, Martin, and Mendis, Dinusha. 2015. Copyright and the Value of the Public Domain: An Empirical Assessment. Intellectual Property Office Research Paper.

Fish, Adam, Rosado Murillo Luis Felipe, Lilly Nguyen, Aaron Panofsky and Christopher M. Kelty. 2011. Birds of the Internet, Journal of Cultural Economy 4 (2): 157-187. http://kelty.org/or/papers/Fish-Birds-2011.pdf.

Ford, Sam. 2015. Social Media Ownership. In The International Encyclopedia of Digital Communication and Society, edited by Robin Mansell et al. Wiley.

Forte, Andrea, Vanessa Larco and Amy Bruckman. 2009. Decentralisation in Wikipedia Governance. Journal of Management Information Systems 26 (1): 49-72. http://andreaforte.net/ForteLarcoBruckmanPrePrint.pdf.

Frischmann, Brett. 2012. Infrastructure: The Social Value of Shared Resources. Oxford University Press.

Fuchs, Christian. 2014. Digital Labour and Karl Marx. Routledge.

Fuchs, Christian and Marisol Sandoval. 2014. Digital Workers of the World Unite! A Framework for Critically Theorising and Analysing Digital Labour. TripleC 12 (2). http://www.triplec.at/index.php/tripleC/article/view/549.

Fung, Archon. 2006. Varieties of Participation. In Complex Governance, Public Administration Review, 66 (s1), 66-75. http://www.archonfung.net/papers/FungVarietiesPAR.pdf.

Fuster Morell, Mayo. 2014a. Governance of Online Creation Communities for the Building of Digital Commons: Viewed through the Framework of the Institutional Analysis and Development. In Knowledge Commons, edited by B. Frischmann, Michael J. Madison, and Katherine J. Strandburg. Oxford University Press. http://www.onlinecreation.info/wpcontent/uploads/2013/07/MFM WorkingPaper IAD OCC.pdf.

Fuster Morell, Mayo et al. 2014b. Theoretical Synthesis. D1.2, P2Pvalue Project. http://p2pvalue.eu/sites/default/files/u28/D12_31July_TheoreticalFindingsA\%20\%281\%29.pdf.

Gillespie, Tarleton. 2010. The Politics of 'Platforms'. New Media and Society 12 (3): 347-364. http://papers.ssrn.com/sol3/papers.cfm?abstract_id=1601487.

Ghosh, Rishab, ed. 2005. Collaborative Ownership and the Digital Economy. MIT Press, 2006.

Guadamuz, Andrés. 2011. Networks, Complexity and Internet Regulation, Cheltenham. UK: Edward Elgar Publishing. https://www.era.lib.ed.ac.uk/handle/1842/7795.

Kelty, Christopher. 2008. Two Bits: The Cultural Significance of Free Software and the Internet, Durham: Duke University Press. http://twobits.net/pub/Kelty-TwoBits.pdf.

Kleiner, Dmytri. 2007. Copyfarleft and Copyjustright. http://www.metamute.org/editorial/articles/copyfarleft-and-copyjustright.

Kostakis, Vasilis. 2013. At the Turning Point of the Current Techno-Economic Paradigm: CommonsBased Peer Production, Desktop Manufacturing and the Role of Civil Society in the Perezian Framework. tripleC 11 (1): 173-190. http://triple-c.at/index.php/tripleC/article/view/463. 
Kreiss, Daniel, Megan Finn and Fred Turner. 2011. The Limits of Peer Production: Some Reminders From Max Weber for the Network Society. New Media and Society 13 (2): 243-259.

Lessig, Lawrence. 1999/2006. Code and Other Laws of Cyberspace. New York: Basic Books. http://codev2.cc/.

Liang, Lawrence. 2005. Guide to Open Content licenses, Piet Zwart Institute. https://archive.org/details/media_Guide to Open_Content Licenses.

Madison, Michael. 2014. Commons at the Intersection of Peer Production, Citizen Science, and Big Data: Galaxy Zoo. In Governing Knowledge Commons, edited by Brett Frischmann, Michael J. Madison, and Katherine J. Strandburg. Oxford University Press. http://arxiv.org/abs/1409.4296.

Mansell, Robin. 2012. Imagining the Internet. Communication, Innovation and Governance. Oxford University Press.

Mansell, Robin. 2015. Platforms of power. Intermedia 43 (1): 20-24. http://eprints.Ise.ac.uk/61318/.

Meng, Bingchun and Wu, Philip F. 2013. Commons/Commodity: Peer Production Caught in the Web of the Commercial Market. Information, Communication and Society 16 (1): 125-145. http://papers.ssrn.com/sol3/papers.cfm?abstract id=1949896.

Mitchell, William. J. 1996. City of Bits. Space, Place and the Infobahn. Cambridge, MA: The MIT Press.

Moglen, Eben. 2010. Freedom In The Cloud: Software Freedom, Privacy and Security for Web 2.0 and Cloud Computing. ISOC Meeting, New York Branch, 5 February 2010. https://www.softwarefreedom.org/events/2010/isoc-ny/FreedomInTheCloud-transcript.html.

Musiani, Francesca. 2015. Nains sans géants. Architecture décentralisée et services Internet. $2^{\text {nd }}$ edn. Paris : Presses des Mines. https://pastel.archives-ouvertes.fr/pastel-00795169.

Ostrom, Elinor. 1990. Governing the Commons: The Evolution of Institutions for Collective Action. Cambridge: Cambridge University Press.

Pollock, Rufus. 2006. The Value of the Public Domain. Report for the Institute for Public Policy Research. http://rufuspollock.org/papers/value of public domain.ippr.pdf.

Reagle, Joseph. 2010. Good Faith Collaboration: The Culture of Wikipedia, Cambridge: MIT Press.

Reidenberg, Joel. 1998. Lex Informatica: The Formulation of Internet Policy Rules Through Technology. Texas Law Review 76 (3). http://ir.lawnet.fordham.edu/cgi/viewcontent.cgi?article=1041andcontext=faculty_scholarship.

Schafer, Valérie, Hervé Le Crosnier and Francesca Musiani. 2011. La neutralité de l'Internet, un enjeu de communication. Paris: CNRS Editions/Les Essentiels d'Hermès.

Scholz, Trebor, ed. 2012. Digital Labor: The Internet as Playground and Factory. Routledge.

Schöpf, Simon. 2015. The Commodification of the Couch: A Dialectical Analysis of Hospitality Exchange Platforms. TripleC 13 (1). http://www.triple-c.at/index.php/tripleC/article/view/480/676.

Schweik, Charles and Robert English. 2012. Internet Success: A Study of Open-Source Software Commons. MIT Press.

Shaw, Aaron. 2012. Centralised and decentralised gatekeeping in an open online collective. Politics and Society 40: 349-388.

Shaw, Aaron, and Benjamin Mako Hill. 2014. Laboratories of Oligarchy? How the Iron Law Extends to Peer Production. Journal of Communication 64 (2): 215-238.

Terranova, Tiziana. 2000, Free Labor: Producing Culture for the Digital Economy. Social Text 6318 (2): 33-58. http://web.mit.edu/schock/www/docs/18.2terranova.pdf.

Tkacz, Nathaniel, Nicolas Mendoza and Francesca Musiani. 2014. Editorial Notes. Journal of Peer Production 4. http://peerproduction.net/issues/issue-4-value-and-currency/editorial-notes/.

van der Graaf, Shenja. 2012. Modonomics: Participation and Competition in Contention. Journal of Gaming and Virtual Worlds 4 (2): 119-135. Bristol: Intellect Ltd. http://papers.ssrn.com/sol3/papers.cfm?abstract id=2030191.

van Dijck, José. 2013. The Culture of Connectivity. A Critical History of Social Media. Oxford University Press.

van Schewick, Barbara. 2010. Internet Architecture and Innovation. Cambridge, MA: The MIT Press.

Vieira, S. Miguel and De Filippi, Primavera. 2014. Between Copyleft and Copyfarleft: Advance Reciprocity for the Commons. Journal of Peer Production 4. http://peerproduction.net/issues/issue-4value-and-currency/invited-comments/between-copyleft-and-copyfarleft-advance-reciprocity-forthe-commons/.

Wittel, Andreas. 2012. Digital Marx: Toward a Political Economy of Distributed Media. tripleC 10 (2): 313-333. http://www.triple-c.at/index.php/tripleC/article/view/379. 
Wu, Tim. 2003. When Code Isn't Law. Virginia Law Review 89 (4): 679-751.

http://papers.ssrn.com/sol3/papers.cfm?abstract id=413201.

Wu, Tim. 2011. The Master Switch: The Rise and Fall of Information Empires. Random House Digital, Inc.

\begin{abstract}
About the Authors
Mélanie Dulong de Rosnay

Melanie Dulong de Rosnay is a researcher in law and technology at the French National Centre for Scientific Research (CNRS) Institute for Communication Sciences, where she leads the Information and Commons Governance research group. She is also a visiting fellow at LSE Department of Media and Communications. She co-founded Communia association on the digital public domain, which she represents at WIPO. She was Creative Commons France legal lead (2003-2013) and worked as a research fellow at the Berkman Center for Internet and Society of Harvard Law School and at the Institute for Information Law of the University of Amsterdam.
\end{abstract}

Francesca Musiani

Francesca Musiani is a researcher at the French National Centre for Scientific Research (CNRS) Institute for Communication Sciences, where she co-leads the research group "Modelization of temporal interactions". She is also an associate researcher at the Centre for the Sociology of Innovation of MINES ParisTech-PSL. Her research work focuses on Internet governance, in an interdisciplinary perspective blending information and communication sciences with Science and Technology Studies (STS). Francesca is a former Yahoo! Fellow in Residence at Georgetown University, the recipient of the 2013 Prix Informatique et Libertés awarded by the French Privacy and Data Protection Commission, and a member of the Commission for Law and Liberties in the Digital Age mandated by the French Parliament. 